\title{
VIII. Speech and Language Development
}

\author{
KAROL K. MUSHER
}

Department of Otorhinolaryngology and Communicative Sciences, Baylor College of Medicine and Department of Speech Pathology, St. Luke's-Texas Children's Hospitals, Houston, Texas, USA

When $D V$ was 8 months old, the Department of Speech Pathology was called for consultation because of an apparent discrepancy between motor development and speech and language development. This impression was substantiated by observation over a period of several months. When he reached the age of 1 year, a speech pathologist began to see him weekly in order to document his progress and initiate therapy, if needed.

His level of performance in the oral receptive and expressive language areas was initially determined exclusively by clinical observation of his play and interaction with others rather than by standarized testing. This was because tests based upon language and experience in a "typical" environment would not be valid and because he was not accustomed to participating in structured tasks, such as pointing to pictures of miniature objects or sitting in a one-to-one test situation. In most cases, the Birth -3 Scale of Bangs and Garrett (5) was used as a reference for making judgments regarding levels of speech and language performance.

At 13 months $D V$ 's receptive language (comprehension), expressive language (ability to communicate), and speech (articulation, structure, and function of the speech mechanism) were assessed. Although he responded to nonverbal sound consistently, his comprehension of language appeared to be poor. He did not seem to understand his name or the word "no"; did not look at objects or people who were in continuous, close contact with him when they were named; and he did not follow simple commands, such as waving "bye-bye" or clapping his hands upon request. Although he did not seem to understand oral language or verbal symbols, he did respond consistently and appropriately to vocal intonation and simple gesture. In general then, his receptive language ability was at about the $6-8$-month level. Expressive language skills were also deficient. His oral language expression was essentially nonexistent and he did not use gesture to communicate. He did not use words or clusters of sounds consistently or appropriately. The quality of his vocalizations was also below expectation for chronologic age. Although his babbling was characterized by changes in inflection, it consisted of only a few vowels and was not used discriminately or for purposes of communication. Only occasionally did he babble while playing alone.

It was not possible to do an audiologic assessment because of the environmental circumstances but there was no reason to suspect a significant hearing loss because he consistently responded to environmental sound, did not rely excessively on visual cues, and there was no evidence of otologic disease. (The presense of adequate hearing sensitivity for speech purposes was later confirmed when he developed speech and language in a normal pattern.) The patient would not cooperate for formal assessment of the peripheral mechanisms of speech, but observation during nonverbal activity indicated grossly normal structure and function for speech purposes.

A broad range of speech and language behavior is accepted as normal in a 1-year-old child. In some instances, the above described speech and language behavior would fall within the normal range. However, in this patient a significant disparity was noted between his motor and language skills which led to further evaluation.

To determine the factor(s) contributing to the speech and language deficit, the child's routine activities and responses to different stimuli were observed by the speech pathologist for approximately $15 \mathrm{~min} / \mathrm{day}$ for 6 weeks. It was concluded that a significant factor in his failure to develop adequate speech and language was probably the absence of a consistent and appropriate language learning environment. The stimulation he received was excessively variable and inconsistent. For example, the patient was called by many different names such as $D V$, "Stinky Poo," "Bambino," by the medical staff and visitors. Similarly, no consistent word such as "bye-bye" was used to indicate departure. The staff often did not have the time, and in some cases were uncertain of how to provide him with appropriate stimulation.

In order to establish a consistent and appropriate language learning environment, a series of lectures and demonstrations on normal language development were held for the staff who cared for him. The precursors of language development, including the role of imitation and babbling, and the relationship between cognitive and linguistic development, were discussed in detail. Key target words initially selected for comprehension, and later for expression, included the patient's name, "no," and "Mama." The word "Mama" was selected upon suggestion of the psychiatrist involved in the case. Since the patient's mother was not in the hospital regularly, her picture was taped on the isolator and reference made to it, so that the verbal label "mama" would be learned and used appropriately. Target words were used consistently, repetitively, and meaningfully and, when appropriate, gestures accompanied the words. Specific ways for encouraging imitation and babbling were demonstrated. Ideas were given for broadening his "language environment" and for making routine activities such as feeding or cleaning the isolator into languagelearning activities. The staff began to verbalize all activities they performed in his presence and to label or describe things they were using or tasks they were doing. They described activities taking place in the street, which were visible through the picture window in $D V$ 's room. They began to talk to him, as a mother does, saying, for instance: "here's the spoon" or "let's wipe it off." They began talking about putting things on, under, in, or behind and comparing size, such as big and little in meaningful situations.

Three months later when expressive and receptive language skills were reassessed, a remarkable improvement was observed in both areas. This suggested he had neither a specific language learning disorder nor a specific problem with the speech mechanism, but that the earlier delay in language development had, in fact, been related to the lack of appropriate and consistent language stimulation! At 16 months, his oral receptive language was judged to be at about the 16-18-month level. Specifically. he identified objects such as a football, frog; chair, and his doll 
by looking at them, retrieving, or touching them. He responded consistently to his name and to simple words. He identified his own body parts and pictures of Mamma, Sister, and Daddy; and he followed simple commands. His expressive language skills were judged to be at the 12 -month level. He babbled consistently while playing and had expanded his repertoir of sounds to include all vowels and combinations of vowels with some consonants. The babbling still did not have specific communicative purpose. He readily engaged in imitation of consonant-vowel combinations, and occasionally attempted new ones. He communicated primarily through gesture; for example, when he wanted to play ball, he would hand the ball to the person and gesture that it be thrown to him. He spontaneously used the words eye and no and the sound unit ha (hot) for coffee and he imitated simple words.

Because providing a conducive environment for speech and language development had worked so well, such stimulation was continued. When language skills were formally assessed 8 months later, at 2 years, his receptive language ability was at about the 2.5 year level. He used single words and phrases consistently and meaningfully. There was no longer a need for him to rely on gesture to communicate. Qualitative analysis of his expressive language revealed that although his syntactic and grammatic patterns were immature, being characterized by developmental errors, the patterns were not deviant. As might be expected, receptive and expressive vocabulary was limited to objects and activities in his environment. He knew the words cylinder, isolator, sterile, but he did not know horse, ring, bus. He knew few names of animals, furniture, fruits, and vegetables, few adjectives of size and color, and few prepositions. His speech, which was easily understood by all without the aid of contextual cues, was characterized by a few developmental articulation errors. His ability to correct these errors with a minimal amount of stimulation was excellent. Voice quality, rate, resonance, and fluency were appropriate.

It was apparent that $D V$ needed only exposure to an experience and to the verbal symbol which represented it in order to understand and use it meaningfully, and that he, in fact, did not have a problem in retention or generalization. In order to assure further linguistic (specifically, in vocabularly, syntax, and grammar) and conceptual development, continued exposure and expansion of his language and experiential environment would be necessary. Suggestions for carrying out this plan were made to the hospital staff and his family, for he was spending $50 \%$ of the time at his home. For example, the family's dining room table was moved into the room with the isolator so that the patient would get an idea of what it was like to sit at a table and eat a meal. He would also be exposed to the language which takes place in such a situation.

The most recent evaluation was done when $D V$ was 3 years old. He was more attentive and cooperative and it was possible to administer some formal tests. His ability to understand single words; as measured by the Peabody Picture Vocabulary Test (Form B) (16) was at the 2-year, 8-month level. He missed items with which he had little experience, such as baking and cone. On Carrow's Auditory Test for Language Comprehension (10), which assessed understanding of grammatic and syntactic structures, he scored at the 4-year, 8-month level. He understood complex structures but had difficulty with vocabulary such as pianist, farmer, painter and with concepts which were not part of his environment. For example, he indicated that most men are doctors and that when a car breaks down, a doctor will come and fix it. His ability to associate auditory verbal stimuli, as measured by the Auditory Association subtest of the Illinois Test of Psycholinguistic Abilities (28), was at the 3-year, 9-month level. On this test also, unfamiliarity with some of the vocabulary (i.e. bounce, desk, drawer) adversely affected his performance. Auditory perceptual functioning including discrimination (Quiet subtest of the Goldman-Fristoe-Woodcock) (20), sequential memory for digits (Illinois Test of Psycholinguistic Abilities), sentences (Binet) (50), and commands, closure, and blending (Illinois Test of Psycholinguistic Abilities) was judged to be above average: He still had not had a formal hearing test, but his speech and language development and his response to verbal and nonverbal sounds suggested that hearing sensitivity was probably within normal limits. His oral expressive language was excellent in terms of sentence length, syntactic and grammatic structures, vocabulary (when considered in relation to his environment), quality of narration, and motivation to use oral language for communication. His connected speech, which was characterized by a frontal lisp, was intelligible at all times and his voice quality, rate, resonance, and fluency were appropriate. He was beginning to show above average ability to understand graphic symbols, specifically letters and numbers.

Language stimulation will be continued in the nursery school situation, which has been created by the team presently working with him. In this manner, his linguistic and conceptual systems should continue to develop. Progress will be monitored. If necessary, direct work on teaching written language will be introduced at an appropriate time.

Pediat. Res. 11: 85-86 (1977)

\title{
IX. Psychiatric Evaluation
}

\author{
DAVID A. FREEDMAN \\ Department of Psychiatry, Baylor College of Medicine, Houston, Texas, USA
}

From infancy, efforts were made to provide this child with affectionate care and environmental stimulation as much like that of normal children as possible under the circumstances of his limited quarters and the barrier between him and the outside world. For instance, as an infant he could be picked up by means of the isolator gloves, handled, jostled. He has an abundance of play objects, dolls, picture books, coloring books, etc., in the isolator. His isolator has always been placed near a picture window where he can see the flow of traffic. He often recognizes his caretakers as they walk from building to building. As he grew 